\title{
Capacidade antioxidante de frutas
}

\author{
Enayde de Almeida Melo*, Maria Inês Sucupira Maciel, Vera Lúcia Arroxelas Galvão de Lima, \\ Rosilda Josefa do Nascimento
}

\author{
Universidade Federal Rural de Pernambuco
}

*Correspondência:

E. A. Melo

Universidade Federal Rural de

Pernambuco - DCD

Av. Dom Manoel de Medeiros, s/n CEP: 52171-900 - Recife - PE, Brasil

E-mail: eamelo@dcd.ufrpe.br
Extratos aquoso e acetônico de 15 frutas foram submetidos a ensaios para investigar a habilidade de seqüestrar o radical estável 1,1-difenil-2-picrilhidrazil (DPPH) e a capacidade de inibir a oxidação em sistema modelo $\beta$-caroteno/ácido linoléico. Todas as frutas exibiram propriedade antioxidante, entretanto a ação foi diferenciada entre elas. $O$ extrato aquoso da acerola, caju, mamão "Formosa", mamão Havai, laranja pêra e goiaba foram os mais eficazes (superior a 70\%), enquanto que o do abacaxi, laranja cravo, manga rosa, melão espanhol, melão japonês, melão orange flesh e pinha apresentaram ação moderada (60-70\%) e o da manga espada e melancia exibiram a mais fraca capacidade de seqüestrar o radical DPPH. Os extratos acetônico da acerola, caju, pinha e goiaba exibiram uma forte capacidade de seqüestrar o radical DPPH (superior a 70\%). Em sistema modelo $\beta$-caroteno/ ácido linoléico, o extrato aquoso da pinha e o acetônico da goiaba exibiram moderada capacidade antioxidante (60-70\%) enquanto que a acerola (extrato aquoso) e o mamão formosa (extrato acetônico) os menores percentuais. Frente à capacidade antioxidante exibida, as frutas podem ser apontadas como fontes de antioxidantes naturais, destacando-se a acerola, caju, mamão Formosa, mamão Havaí, goiaba, laranja pêra, e a pinha por terem apresentado uma potente capacidade antioxidante.

\section{INTRODUÇÃO}

As frutas, reconhecidas fontes de vitaminas, minerais e fibras, são alimentos nutricionalmente importantes da dieta. No entanto, nos últimos anos, maior atenção tem sido dada a estes alimentos uma vez que evidências epidemiológicas têm demonstrado que o consumo regular de vegetais está associado à redução da mortalidade e morbidade por algumas doenças crônicas não transmissíveis. O efeito protetor exer- cido por estes alimentos tem sido atribuído à presença de fitoquímicos com ação antioxidante, dentre os quais se destacam os polifenóis (Wang, Cao, Prior, 1996; Bravo, 1998; Martinez-Valverde, Periago, Ros, 2000; Kaur, Kapoor, 2002).

Os polifenóis, produtos secundários do metabolismo vegetal, constituem um amplo e complexo grupo de fitoquímicos, com mais de 8000 estruturas conhecidas (Bravo, 1998; Martinez-Valverde, Periago, Ros, 2000). 
Este diversificado grupo de compostos encontra-se dividido em várias classes, segundo o esqueleto carbônico dos fitoquímicos, dentre as quais se destacam a dos ácidos fenólicos e a dos flavonóides, entre outras. A capacidade antioxidante dos polifenóis é devida, principalmente, as suas propriedades redutoras, cuja intensidade da ação antioxidante exibida por estes fitoquímicos é diferenciada uma vez que depende, fundamentalmente, do número e posição de hidroxilas presentes na molécula (Rice-Evans, Miller, Paganga, 1997; Ou et al., 2002).

As frutas, principais fontes dietéticas de polifenóis, em função de fatores intrínsecos (cultivar, variedade, estádio de maturação) e extrínsecos (condições climáticas e edáficas) apresentam, em termos quantitativos e qualitativos, composição variada desses constituintes. Por sua vez, eficácia da ação antioxidante depende da estrutura química e da concentração destes fitoquímicos no alimento. Desta forma, este trabalho teve como objetivo avaliar a capacidade antioxidante de frutas comercializadas em RecifePE através da capacidade de seqüestrar o radical estável 1,1-difenil-2-picrilhidrazina (DPPH) e da inibição da oxidação lipídica no sistema modelo $\beta$-caroteno/ácido linoléico.

\section{MATERIAL E MÉTODOS}

\section{Material}

Abacaxi (Ananás comosus L. var. pérola), acerola (Malpighia emarginata D.C.), caju (Anarcadium occidentale), goiaba (Psidium guajava), laranja cravo (Citrus bergamia Risso), laranja pêra (Citrus sinensis L.), mamão Formosa ( Carica papaya L. var. formosa), mamão Havaí (Carica papaya L. var. solo), manga espada (Mangifera indica L. var espada), manga rosa (mangifera indica L. var. rosa), melancia (Citrullus lanatus), melão espanhol (Cucumis melo L. var. reticulares), melão japonês (Cucumis melo L. var. inodorus), melão orange flesh ( Cucumis melo L. var. orange flesh), pinha (Annona squamosa) foram adquiridas mensalmente no comércio local, respeitando o calendário de comercialização da CEAGEPE (Companhia de Abastecimento e Armazéns Gerais de Pernambuco) no qual é indicado o período de alta oferta dos produtos no mercado. Cada fruta foi adquirida em três diferentes meses, do período de uma mesma safra, para constituir três amostras independentes, e as determinações analíticas de cada amostra foram realizadas em duplicata. Ao final do período experimental (1 ano), 15 frutas foram analisadas quanto à capacidade antioxidante, no Laboratório de Análises Físico-químicas de Alimentos do Departamento de Ciências Domésticas da UFRPE.

\section{Métodos}

\section{Preparo da amostra}

As frutas foram descascadas e a porção comestível desintegrada em multiprocessador (Wallita). Dependendo do teor de fenólicos totais, uma alíquota de 20 a $300 \mathrm{~g}$ da polpa desintegrada foi adicionada à água destilada, na proporção de 1:2 (p/v), quando necessário, e em seguida filtrada. O resíduo, após a adição de $30 \mathrm{~mL}$ de água destilada, foi submetido à agitação permanente, a temperatura ambiente $\left(22 \pm 2^{\circ} \mathrm{C}\right)$, por 20 minutos. Esta etapa foi repetida por duas vezes, totalizando 40 minutos de extração. Os filtrados resultantes (extrato aquoso) foram combinados, concentrados sob pressão reduzida a $40^{\circ} \mathrm{C}$, o volume final aferido para $50 \mathrm{~mL}$.

Para a obtenção de extrato acetônico, o resíduo proveniente da extração aquosa foi mantido, por 20 minutos, sob agitação permanente, em $30 \mathrm{~mL}$ de acetona a $80 \%$, a temperatura ambiente $\left(22 \pm 2^{\circ} \mathrm{C}\right) \mathrm{e}$, em seguida, filtrado. $\mathrm{O}$ resíduo foi novamente submetido ao processo de extração, acima explicitado, por mais dois períodos de 20 minutos, totalizando um tempo de extração de 60 minutos. Os filtrados resultantes (extrato acetônico) foram combinados, concentrados sob pressão reduzida a $40^{\circ} \mathrm{C}$ e o volume final aferido para $50 \mathrm{~mL}$. O extrato aquoso e acetônico foram submetidos à determinação do teor de fenólicos totais e aos ensaios da atividade antioxidante.

\section{Fenólicos totais}

O teor de fenólicos totais do extrato aquoso e acetônico das frutas foi determinado, segundo metodologia descrita por Wettasinghe e Shahidi (1999), utilizando o reagente Folin-Ciocalteau (Merck) e curva padrão de catequina. Os resultados foram expressos em $\mu \mathrm{g}$ de fenólicos totais em equivalente de catequina por $\mathrm{mL}$ do extrato.

\section{Ensaios da atividade antioxidante}

$\mathrm{O}$ extrato aquoso e acetônico, isoladamente, foram submetidos aos seguintes ensaios:

1) Capacidade de seqüestrar o radical 1,1-difenil-2picrilhidrazil (DPPH), segundo método descrito por BrandWilliams et al. (1995), modificado por Miliauskas et al. (2004). Alíquotas $(0,2 \mathrm{~mL})$ do extrato aquoso e acetônico das frutas, com concentrações de fenólicos totais de 31,51 a $161,61 \mu \mathrm{g}$ e de 2,24 a $125,97 \mu \mathrm{g}$, respectivamente, foram colocadas em diferentes tubos de ensaio. Em seqüência, 3,9 $\mathrm{mL}$ da solução de DPPH em metanol $\left(5 \times 10^{-5} \mathrm{M}\right)$ foram adicionados e, após agitação, os tubos foram deixados em repouso ao abrigo da luz. Ao final de 15 minutos a absorbância foi medida a $515 \mathrm{~nm}$ e a capacidade de seqüestrar o radical, expressa em percentual, calculada em rela- 
ção ao controle (sem antioxidante), segundo a expressão abaixo:

$\%$ seqüestro $=\frac{\text { Absorbância do controle }- \text { Absorbância da amostra } X 100}{\text { Absorbância do controle }}$

2) Oxidação acoplada do $\beta$-caroteno e ácido linoléico, segundo a metodologia descrita por Marco (1968), modificada por Hammerschmidt e Pratt (1978), como segue: A solução de $\beta$-caroteno $(1 \mathrm{~mL})$, preparada pela dissolução de $1 \mathrm{mg}$ de $\beta$-caroteno em $10 \mathrm{~mL}$ de clorofórmio, foi colocada em um balão de fundo redondo, contendo $20 \mathrm{mg}$ de ácido linoléico e $200 \mathrm{mg}$ do emulsificante Tween 20. Após a remoção do clorofórmio, em evaporador rotatório a $50^{\circ} \mathrm{C}, 50 \mathrm{~mL}$ de água destilada foram adicionados sob agitação vigorosa. Alíquotas $(5 \mathrm{~mL})$ desta emulsão foram transferidas para uma série de tubos de ensaios contendo $0,2 \mathrm{~mL}$ do extrato aquoso e acetônico das frutas, com concentração de fenólicos totais de 31,51 a $161,61 \mu \mathrm{g}$ e de 2,24 a $125,97 \mu \mathrm{g}$, respectivamente. Em seguida, os tubos foram colocados em banho-maria a $50^{\circ} \mathrm{C}$, durante $105 \mathrm{~min}$, e a absorbância registrada no comprimento de onda de $470 \mathrm{~nm}$. A capacidade antioxidante foi expressa como percentual de inibição da oxidação, calculada em relação a $100 \%$ da oxidação do controle (sem antioxidante), conforme expressão abaixo:

$\%$ de inibição $=\frac{\text { Taxa de degradação do controle }- \text { taxa de degradação da amostra } \times 100}{\text { Taxa de }}$

Em virtude do elevado teor de fenólicos totais, os extratos aquoso e acetônico da acerola foram diluídos na proporção de 1:10 e de 1:5, respectivamente, para serem submetidos aos ensaios da atividade antioxidante. Como termo de comparação foi utilizada a capacidade antioxidante e a capacidade de seqüestrar o radical DPPH do BHT $(120 \mu \mathrm{g} / 0,2 \mathrm{~mL})$ determinadas nas mesmas condições dos dois ensaios acima descritos.

\section{Tratamento estatístico dos dados}

Todas as determinações foram efetuadas em triplicata (três amostras de cada fruta adquirida em três diferentes ocasiões), os dados obtidos foram submetidos à análise de variância e Teste de Tukey, ao nível de significância de 5\%, utilizando o programa estatístico "Statistica for Windows" (StatSoft, Inc. versão 5.5). O coeficiente de correlação para determinar a relação entre as variáveis, teor de fenólicos totais e capacidade antioxidante dos extratos das frutas, foi calculado e a análise de regressão efetuada, usando o mesmo programa estatístico acima citado.

\section{RESULTADOS E DISCUSSÃO}

Os vegetais, em particular as frutas, apresentam em sua constituição vários compostos com ação antioxidante, os quais incluem o ácido ascórbico, carotenóides e polifenóis. A quantidade e o perfil destes fitoquímicos variam em função do tipo, variedade e grau de maturação da fruta bem como das condições climáticas e edáficas do cultivo (Leong, Shui, 2002). Para avaliar a capacidade antioxidante de um vegetal se faz necessário obter o máximo de extração dos compostos bioativos, os quais apresentam polaridade diferenciada. Desta forma, a solubilidade em um determinado solvente é característica peculiar do fitoquímico, o que explica a inexistência de um procedimento de extração universal.

O uso da água (100\%) no processo possibilitou a extração de um maior teor de polifenóis, pois o extrato aquoso de todas as frutas, com exceção da pinha, exibiu maior teor de fenólicos totais do que o extrato acetônico (Tabela 1). Evidencia-se, portanto, que a maior parte dos compostos fenólicos dessas frutas apresentam maior polaridade, portanto são mais hidrossolúveis. Dentre os extratos de frutas estudados, destaca-se o extrato aquoso e acetônico da acerola, seguido pelo do caju, com o mais elevado teor de fenólicos totais, enquanto que o extrato aquoso da manga espada, seguida pelo da manga rosa, e o extrato acetônico do mamão Havaí e o do abacaxi com o menor teor destes constituintes.

No que se refere à capacidade de seqüestrar o radical DPPH, expressa em percentual de seqüestro (Figura 1) evidencia-se que o(s) composto(s) ativo(s) presente(s) nos extratos atua $(\mathrm{m})$ como doador de hidrogênio ao radical, entretanto esta ação é diferenciada entre as frutas. A capacidade de seqüestro de todos os extratos acetônicos, exceto o da acerola, goiaba, manga espada e pinha, foi menor do que a exibida pelos extratos aquosos, possivelmente devido à diversidade dos componentes bioativos extraídos pelos procedimentos de extração utilizados, especialmente no que se refere à classe dos compostos. Wu et al. (2004), avaliando a ação antioxidante de frutas disponíveis no mercado dos Estados Unidos, evidenciaram que a fração hidrofílica, na qual os compostos fenólicos predominavam, apresentou a maior capacidade de seqüestrar radical livre pelo método ORAC (capacidade de absorção do radical oxigênio) do que a fração lipofílica. Estes autores ressaltam que os compostos fenólicos da fração hidrofílica são responsáveis por mais de $90 \%$ da capacidade antioxidante total das frutas estudadas.

Os extratos de frutas que exibiram percentual de seqüestro acima de $70 \%$, entre 50 e $70 \%$ e abaixo de $50 \%$ foram classificados como extratos de frutas com forte, 
TABELA I - Teor de fenólicos totais em extrato aquoso e acetônico de frutas.

\begin{tabular}{lccc}
\hline Frutas & \multicolumn{2}{c}{ Fenólicos totais em equivalente de catequina $(\mu \mathrm{g} / \mathrm{mL})$} & Total \\
\hline Abacaxi & Extrato aquoso & $75,25 \pm 3,76$ & $590,80 \pm 28,54$ \\
Acerola & $515,55 \pm 24,77$ & $1.595,50 \pm 63,82$ & $4.962,05 \pm 65,57$ \\
Caju & $3.366,55 \pm 67,33$ & $629,85 \pm 31,49$ & $1.437,90 \pm 71,89$ \\
Goiaba & $808,05 \pm 32,32$ & $331,17 \pm 13,38$ & $799,69 \pm 13,72$ \\
Laranja cravo & $468,52 \pm 14,06$ & $146,30 \pm 8,79$ & $555,30 \pm 9,53$ \\
Laranja pêra & $409,00 \pm 12,27$ & $208,10 \pm 8,32$ & $673,35 \pm 18,12$ \\
Mamão Formosa & $465,25 \pm 27,92$ & $106,45 \pm 5,05$ & $615,45 \pm 14,98$ \\
Mamão Havaí & $509,00 \pm 22,91$ & $11,20 \pm 0,68$ & $296,05 \pm 10,54$ \\
Manga espada & $284,85 \pm 17,09$ & $99,45 \pm 7,94$ & $257,00 \pm 6,75$ \\
Manga rosa & $157,55 \pm 5,51$ & $84,15 \pm 3,27$ & $257,60 \pm 6,85$ \\
Melancia & $173,45 \pm 6,94$ & $257,40 \pm 10,87$ & $712,35 \pm 12,50$ \\
Melão espanhol & $454,95 \pm 13,65$ & $130,75 \pm 8,73$ & $514,65 \pm 13,46$ \\
Melão japonês & $383,90 \pm 16,19$ & $276,30 \pm 13,85$ & $851,35 \pm 18,85$ \\
Melão orange flesh & $575,05 \pm 21,85$ & $156,70 \pm 8,35$ & $629,35 \pm 18,35$ \\
Pinha & $472,65 \pm 28,36$ & $404,10 \pm 20,21$ & $583,45 \pm 15,69$ \\
\hline
\end{tabular}

Os valores referem-se a média de três determinações (três amostras independentes)

moderada e fraca capacidade de seqüestro, respectivamente. Na Figura 1 evidencia-se que, em ordem decrescente, os extratos aquosos da acerola, mamão Formosa, caju e mamão Havaí, além de apresentarem uma forte capacidade antioxidante, foram os mais eficazes em seqüestrar o radical livre, cujo percentual de seqüestro foi superior ao antioxidante sintético BHT. A laranja pêra, embora tenha exibido ação antioxidante estatisticamente semelhante a do BHT, integra o grupo das frutas com forte capacidade antioxidante, uma vez que o percentual de seqüestro do radical DPPH foi superior a 70\%. Com exceção do extrato aquoso do abacaxi, goiaba, laranja cravo, melão japonês, com capacidade antioxidante moderada (50-70\% de seqüestro), as demais frutas, com percentual de seqüestro inferior a 50\%, exibiram uma fraca capacidade em seqüestrar o radical DPPH. Dentre as frutas com menor capacidade de seqüestro destacam-se a melancia, melão orange, manga rosa, manga espada e a pinha. Resultado semelhante foi obtido por Kuskoski et al. (2005) para polpa congelada de acerola e a pinha que se destacaram dentre as polpas estudadas por terem apresentado, respectivamente, a maior e menor capacidade de seqüestro do radical DPPH.

Os extratos acetônico da acerola, caju, pinha e goiaba exibiram uma forte capacidade de seqüestrar o radical DPPH (superior a 70\%), no entanto, a capacidade de seqüestro dos extratos da acerola e caju foi significativamente superior a do antioxidante sintético BHT (Figura 1). Os demais extratos, com exceção do extrato do mamão Formo-

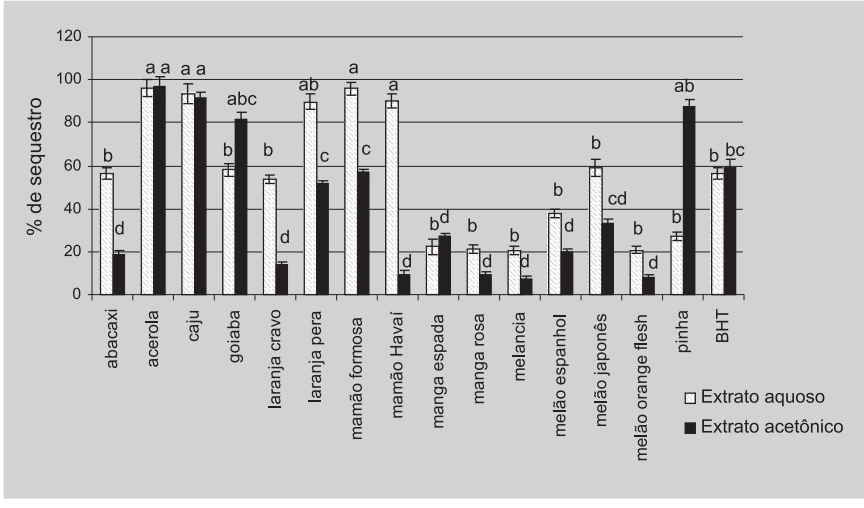

FIGURA 1 - Capacidade de seqüestrar o radical DPPH (\% de seqüestro) do extrato aquoso e acetônico de frutas. (Letras iguais nas colunas respectivas aos extratos, aquoso e acetônico, não diferem estatisticamente entre si pelo Teste de Tukey $(\mathrm{p}>0,05)$.

sa e da laranja pêra com ação moderada, apresentaram uma fraca capacidade de seqüestro. $\mathrm{O}$ extrato acetônico do mamão Havaí e da melancia destacam-se por exibir o menor percentual de seqüestro.

Segundo a capacidade de seqüestrar o radical ABTS (2,2'-azinobis-3-etilbenzotiazolina-6-ácido sulfônico), Leong e Shui (2002) classificaram a goiaba com elevada capacidade, a laranja, mamão, manga e abacaxi com média capacidade e a melancia com baixa capacidade de seqüestro. Esta classificação foi semelhante à do extrato 
acetônico deste estudo, exceto para o extrato do abacaxi, laranja cravo e a manga rosa que exibiram uma fraca capacidade de seqüestro do radical DPPH. Estes autores ressaltaram que a contribuição do ácido ascórbico no seqüestro desse radical variou extensivamente entre as frutas. No abacaxi, goiaba, mamão, melancia e laranja, a contribuição do ácido ascórbico foi de 63, 48,3, 48, 31,7 e 25\%, respectivamente, embora, Wang et al. (1996) tenham relatado que o percentual de contribuição do ácido ascórbico na ação antioxidante das frutas é inferior a 15\%. Em suco de 5 variedades de laranja foi evidenciado uma forte e uma fraca correlação entre o teor de fenólicos e a capacidade antioxidante e entre o teor de ácido ascórbico e a capacidade antioxidante, respectivamente (Rapisarda et al., 1999). É possível que ácido ascórbico e carotenóides, além dos polifenóis, estejam presentes nos extratos testados, os quais podem estar contribuindo sinérgica ou antagonicamente com capacidade antioxidante das frutas analisadas. Entretanto, a participação de outros componentes não reduz a relevância da ação antioxidante dos polifenóis.

O teor de fenólicos totais e o percentual de seqüestro do radical DPPH dos extratos (aquoso e acetônico) das frutas apresentaram uma fraca e uma média correlação $(\mathrm{R}=$ $0,4488$ e 0,$7142 ; p<0,05)$, respectivamente. Na análise de regressão $(p<0,05)$ evidencia-se que não houve um aumento linear da capacidade de seqüestrar o radical DPPH em função do teor de fenólicos totais (Figura 2). Vários autores têm demonstrado de forma conclusiva que existe uma forte relação positiva entre o teor de fenólicos totais e a capacidade antioxidante de frutas e hortaliças (Vison et al., 1998; Velioglu et al., 1998; Kaur, Kapoor, 2002; Abdille et al., 2005), enquanto que outros autores não têm evidenciado esta correlação (Kahkonen et al., 1999; Ismail et al., 2004). Além da presença nos extratos de outros fitoquímicos, a estrutura química do componente ativo tem influência sobre a eficácia do antioxidante natural, uma vez que a posição e o número de hidroxilas presentes na molécula dos polifenóis é um fator relevante para esta atividade. Segundo Shahidi, Janitha e Wanasundara (1992), a orto-dihidroxilação contribui marcadamente para a capacidade antioxidante do composto. Assim, a capacidade antioxidante de um extrato não pode ser explicada apenas com base em seu teor de fenólicos totais, a caracterização da estrutura do composto ativo, também, é necessária (Heinonen, Lehtonen, Hopia, 1998).

A capacidade antioxidante do extrato aquoso e acetônico das frutas, também, foi avaliada no sistema modelo $\beta$-caroteno/ácido linoléico, cujos resultados variaram de 3,33 a $61,03 \%$ e de 3,89 a 67,25\% de inibição, respectivamente (Figura 3). Com exceção do extrato aquoso do abacaxi, mamão Havaí, manga espada, manga rosa e pinha, os extratos das demais frutas exibiram menor capacidade antioxidante
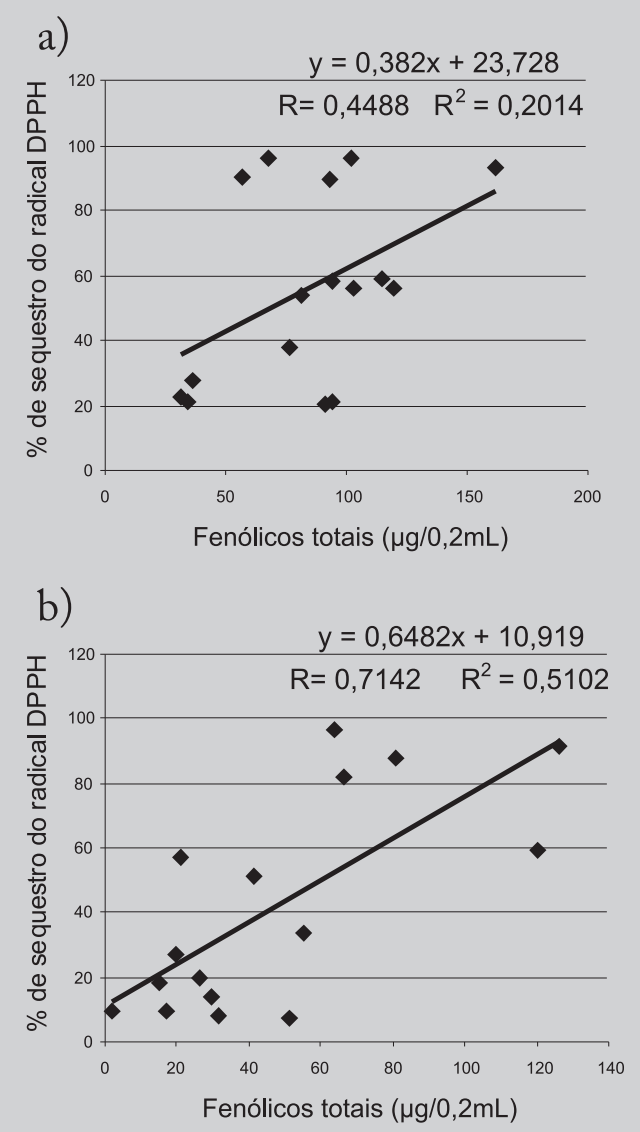

FIGURA 2 - Relação entre o teor de fenólicos totais e a capacidade de seqüestrar o radical DPPH (\%) do extrato aquoso (A) e acetônico (B) de frutas.

do que os extratos acetônicos. Evidencia-se, portanto, que os compostos bioativos presentes nos extratos, reduziram, em graus diferentes, o descoramento do $\beta$-caroteno.

Em função do percentual de inibição exibido, a pinha (extrato aquoso) e goiaba (extrato acetônico) foram classificadas como frutas com moderada capacidade antioxidante (50 a 70\%), cuja ação foi estatisticamente inferior e semelhante, respectivamente, ao antioxidante sintético BHT. As demais frutas (extrato aquoso e acetônico), por exibirem percentual de inibição da oxidação inferior a $50 \%$, foram considerados com fraca capacidade antioxidante, dentre os quais se destacaram o mamão Formosa (extrato aquoso) e a acerola (extrato acetônico) com os menores percentuais. Em acerolas maduras, provenientes da cidade de Japurá-PR, o teor de fenólicos totais foi de $1.350 \mu \mathrm{g} / \mathrm{g}$ e a atividade antioxidante de $44,7 \%$ de inibição de formação de dienos conjugados a partir da oxidação do metil linoleato (Righetto et al., 2005). A capacidade antioxidante determinada por este método foi muito superior à encontrada neste estudo. 


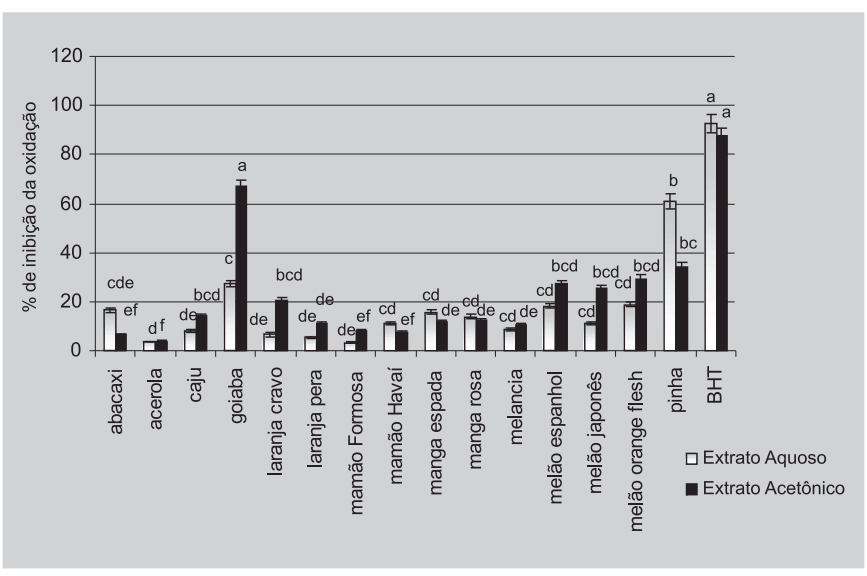

FIGURA 3 - Capacidade antioxidante do extrato aquoso e acetônico de frutas (contendo 31,51 a 161,61 $\mu \mathrm{g}$ e de 2,24 a $125,97 \mu \mathrm{g}$ de fenólicos totais/0,2mL, respectivamente) determinada pela oxidação acoplada do b-caroteno/ácido linoléico. (Letras iguais nas colunas respectivas aos extratos, aquoso e acetônico, não diferem estatisticamente entre si pelo Teste de Tukey $(\mathrm{p}>0,05)$

Na relação entre o teor de fenólicos totais e a capacidade antioxidante (\% de inibição da oxidação) do extrato aquoso das frutas, apresentada na Figura 4, evidenciase uma fraca correlação negativa $(p<0,05)(R=-0,3970$; $\left.\mathrm{R}^{2}=0,1576\right)$ entre estas variáveis, enquanto que uma fraca correlação positiva $(\mathrm{p}<0,05)\left(\mathrm{R}=0,2881 ; \mathrm{R}^{2}=0,0830\right)$ foi observada no extrato acetônico. Kaur e Kapoor (2002), usando o reagente Folin Ciocalteau para determinação de teor de fenólicos e o sistema modelo $\beta$-caroteno/ ácido linoléico para avaliar a capacidade antioxidante em extrato etanólico de hortaliças, evidenciaram uma moderada e positiva correlação entre estas variáveis.

A ação dos extratos das frutas testadas nos dois ensaios (DPPH e $\beta$-caroteno/ ácido linoléico) foi diferenciada. Enquanto no ensaio do DPPH, o extrato aquoso e acetônico da acerola exibiram a maior capacidade de seqüestrar o radical, no ensaio $\beta$-caroteno/ ácido linoléico estes extratos apresentaram um dos menores percentuais de inibição da oxidação. Este comportamento foi semelhante para as demais frutas, com exceção do extrato aquoso da pinha cujo percentual de inibição da oxidação (ensaio $\beta$ caroteno/ ácido linoléico) foi levemente superior ao percentual de seqüestro do radical DPPH. Duarte-Almeida et al. (2006) obtiveram resposta semelhante para o extrato metanólico de acerola que no método de seqüestro do DPPH apresentou a maior capacidade antioxidante enquanto que no sistema $\beta$-caroteno/ ácido linoléico comportou-se como pró-oxidante. Segundo estes autores, o ácido ascórbico em elevada concentração após doar os dois hi-

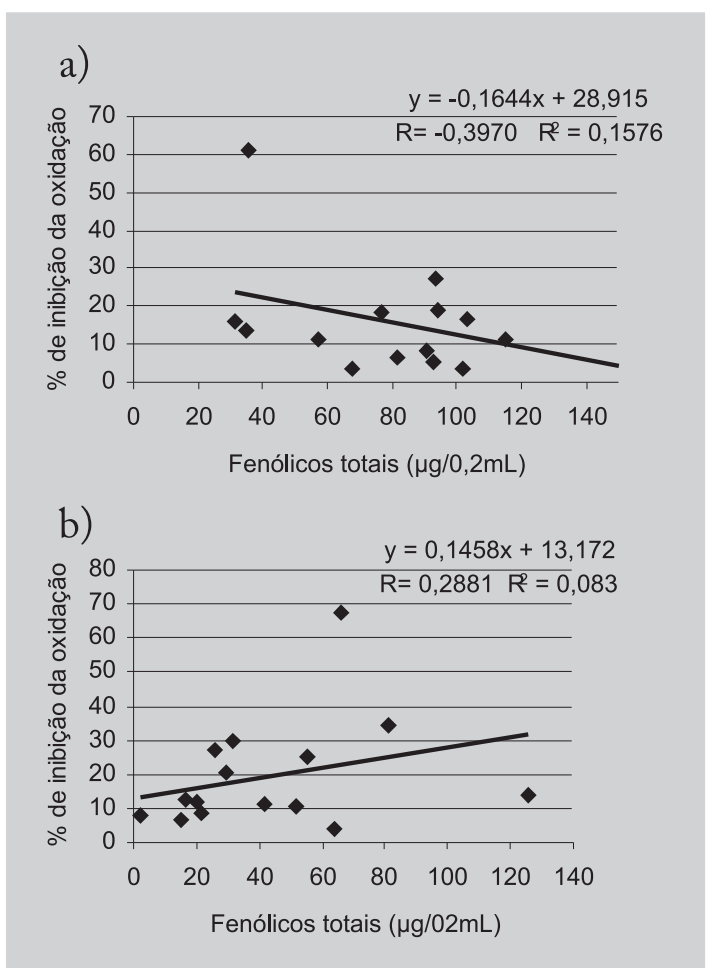

FIGURA 4 - Relação entre o teor de fenólicos totais e a capacidade antioxidante ( $\%$ de inibição) do extrato aquoso (a) e acetônico (b) de frutas comercializadas em Recife determinada pela oxidação acoplada do $\beta$-caroteno/ácido linoléico.

drogênios redutores deu origem ao radical ascorbila, tornando-se suscetível à captação de elétrons, passando a agir como oxidante. Como o método de seqüestro do DPPH se baseia na transferência de elétrons de um composto antioxidante para o radical livre, o poder redutor do composto a ser testado é avaliado. Neste caso, as substâncias pró-oxidantes não são detectadas. Assim, as discrepâncias evidenciadas podem ser inerentes às características e o mecanismo de ação do(s) composto(s) bioativo(s) e a metodologia utilizada para avaliar sua capacidade antioxidante. Não obstante as respostas dos extratos terem sido diferentes nos dois ensaios, as frutas estudadas integram o grupo de alimentos com capacidade antioxidante considerável, tornando-se imprescindível a sua presença na dieta usual de modo a proteger o organismo dos danos oxidativos.

\section{CONCLUSÃO}

Todas as frutas estudadas apresentaram capacidade antioxidante, entretanto a intensidade desta ação foi diferenciada entre elas. A acerola, caju, mamão Formosa, mamão Havaí, goiaba, laranja pêra, e a pinha destacaram- 
se por terem apresentado uma potente capacidade antioxidante. Frente à ação antioxidante exibida, as frutas podem ser apontadas como boas fontes de antioxidantes naturais que podem ser mais efetivas e econômicas do que o uso de suplementos dietéticos na proteção do organismo contra os danos oxidativos, portanto, o seu consumo deve ser estimulado.

\section{ABSTRACT \\ Antioxidant capacity of the fruits}

Aqueous and acetone extracts from 15 fruits have been screened for antioxidant activity using DPPH method and $\beta$-carotene/linoleic acid model. All fruits studied showed antioxidant activity, but in different extent. Acerola, cashew-apple, papaya "formosa", papaya "solo", orange and guava showed the higher antioxidant activity (>70\%) in DPPH method, followed by pineapple, bergamont, mango "rosa", melon "reticulares", melon "inodorus", melon "orange flesh" and sugar-apple aqueous extract (moderate, 60-70\%) and mango "espa$d a$ " and watermelon aqueous extract, the lowest activity. Acerola, cashew-apple, sugar-apple and guava acetone extracts exhibited higher scavenging activity toward DPPH radicals (>70\%). $\beta$-carotene/linoleic acid model index of sugar-apple aqueous extract and guava acetone extract demonstrated moderate antioxidant activity (60$70 \%$ ), meanwhile acerola aqueous extract and papaya "formosa" acetone extract the lower. According to antioxidant activity, fruits can be indicated as natural antioxidants sources, pointing out acerola, cashew-apple, papaya "solo", papaya "formosa", guava, orange and sugar-apple as the highest in antioxidant capacity.

UNITERMS: Antioxidant activity/Fruits. DPPH free radical scavenging. $\beta$-carotene/linoleic acid model system.

\section{AGRADECIMENTOS}

AFACEPE (Edital PP) e ao CNPq (Edital Universal) pelos auxílios financeiros.

\section{REFERÊNCIAS BIBLIOGRÁFICAS}

ABIDILLE, M.D.H.; SINGH, R.P.; JAYAPRAKASHA, G.K.; JENA, B.S. Antioxidant activity of the extracts from Dillenia indica fruits. Food Chem, Washington, v.90, p.891-896, 2005.
BRAND-WILLIAMS, W.; CUVELIER, M.E.; BERSET, C. Use of free radical method to evaluate antioxidant activity. Lebensm-Wiss. Techonol., London, v.28, p.25-30, 1995.

BRAVO, L. Polyphenols: chemistry, dietary sources, metabolism and nutritional significance. Nutr. Rev., Washington, v.56, n.11, p.317-333, 1998.

BIANCHI, M.L.P.; ANTUNES, L.M.G. Radicais livres e os principais antioxidantes da dieta. Rev. Nutr., Campinas, v.12, n.2, p.123-130, 1999.

BURTON, G.W. Antioxidant action of carotenoids. J. Nutr., Philadelphia, v.119, n.1, p.109-111, 1989.

CHEESEMAN, K.H.; SLATER, T.F. Uma introdução à bioquímica dos radicais livres. In: Radicais livres em medicina. Rio de Janeiro: Interlivros, 1996. p.1-13.

DESHPANDE, S.S.; DESHPANDE, U.S.; SALUNKHE, D.K. Nutritional and health aspects of food antioxidants. In: MADHAVI, D.L.; DESHPANDE, S.S.; SALUNKHE, D.K. Food antioxidants - technological, toxicological and health perspectives. New York: Marcel Dekker, 1995. p.361-469.

FRANKEL, E.N.; MEYER, A.S. The problems of using onedimensional methods to evaluate multifunctional food and biological antioxidants. J. Sci Food Agric., Chichester, v.80, n.13, p.1925-1941, 2000.

HALLIWELL, B. Antioxidants in human health and disease. Annu. Rev. Nutr, Palo Alto, v.16, p.33-50, 1996.

HAMMERSCHMIDT, P.A.; PRATT, D.E. Phenolic antioxidants of dried soybeans. J. Food Sci., Chicago, v.43, p.556-559, 1978.

HARBORNE, J.B. Phytochemical methods. London: Chapman and Hall, 1973. p.33-88.

HEINONEN, M.; LEHTONEN, P.J.; HOPIA, A. Antioxidative activity of berry and frut wines and liquor. J. Agric. Food Chem., Washington, v.48, p.25-31, 1998.

HERRMANN, K. Flavonol and flavones in food plants: a review. J. Food Technol, Chicago, v.11, p.433-448, 1976.

ISMAIL,A.; MARJAN, Z.M.; FOONG C.W. Total antioxidant activity and phenolic content in selected vegetables. Food Chem., Washington, v.87, p.581-586, 2004. 
JACOB, R.A.; BURRI, B. Oxidative damage and defense. Am. J. Clin. Nutr., Bethesda, v.63, p.985-990, 1996.

JORGENSEN, K.; SKIBSTED, L.H. Carotenoid scavenging of radicals - effect of carotenoid structure and oxygen partial pressure on antioxidative activity. Z. Lebensm.Unters. Forsch., Berlin, v.196, n.5, p.423-429, 1993.

KAHKONEN, M.P.; HOPIA, A.I.; VUORELA, H.J.; RAUHA, J-P.; PIHLAJA, K.; KUJALA, T.S.; HEINONEN, M. Antioxidant activity of plan extracts containing phenolic compounds. J. Agric. Food Chem., Washington, v.47, p.3954-3962, 1999.

KAUR, C.; KAPOOR, H.C. Anti-oxidant activity and total phenolic content of some Asian vegetables. Int. J. Food Sci. Technol., Oxford, v.37, p.153-161, 2002.

KRINSKY, N.I. Antioxidant functions of carotenoids. Free Radic. Biol. Med., New York, v.7, p.617-635, 1989.

KUSKOSKI, E.M.; ASUERO, A.G.; TRONCOSO, A.M.; MANCINI FILHO, J.; FETT, R. Aplicación de diversos métodos químicos para determinar actividad antioxidante em pulpa de frutos. Cien. Tecnol. Aliment., Campinas, v.25, n.4, p.726-732, 2005.

LEONG, L.P.; SHUI, G. An investigation of antioxidant capacity of fruit in Singapore markets. Food Chem., Washington, v.76, p.69-75, 2002.

MARCO, G.J. A rapid method for evaluation of antioxidants. J. Am. Oil Chem. Soc., Champaign, v.45, p.594-598, 1968.

MARTINEZ-VALVERDE, I.; PERIAGO, M.J.; ROS, G. Significado nutricional de los compuestos fenólicos de la dieta. Arch. Latinoam. Nutr., Caracas, v.50, n.1, p.5-18, 2000.

MILIAUSKAS, G.; VENSKUTONIS, P.R.; VAN BEEK, T.A. Screening of radical scavenging activity of some medicinal and aromatic plant extracts. Food Chem., Washington, v.85, p.231-237, 2004.

MOLYNEUX, P. The use of the stable free radical diphenylpicryl-hydrazil (DPPH) for estimating antioxidant activity. Songklanakarin J. Sci. Technol, Hat Yai, v.26, n.2, p.211-219, 2003.
NAMIKI, M.Antioxidants /antimutagens in food. CRC-Crit. Rev. Food Sci. Nutr., Philadelphia, v.29, p.273-300, 1990.

PIETTA, P.G. Flavonoids as antioxidants. J. Nat. Prod., Cincinnati, v.63, n.7, p.1035-1042, 2000.

RAPISARDA, P.; TOMAINO, A.; LO CASCIO, R.; BONINA, F.; PASQUALE, A.; SAIJA, A. Antioxidant effectiveness as influenced by phenolic content of fresh orange juices. J. Agric. Food Chem., Washington, v.47, n.11, p.4718-4723, 1999.

RICE-EVANS, C.A.; MILLER, N.J.; PAGANGA, G. Antioxidant properties of phenolic compounds. Trends Plant Sci., Oxford, v.4, p.304-309, 1997.

RICE-EVANS, C.A.; MILLER, N.J.; PAGANGA, G. Structure antioxidant activity relationship of flavonoids and phenolic acid. Free Radic. Biol. Med., New York, v.20, n.7, p.933-956, 1996.

RIGHETTO, A.M.; NETTO, F.M.; CARRARO, F. Chemical composition and antioxidant activity of juices from mature and immature acerola (Malpighia emarginata DC). Food Sci. Technol. Int., Washington, v.11, n.4, p.315-321, 2005.

SHAHIDI, F.; JANITHA, P.K.; WANASUNDARA, P.D. Phenolic antioxidants. CRC-Crit. Rev. Food Sci. Nutr. Philadelphia, v.32, n.1, p.67-103, 1992.

VANNUCCHI, H.; JORDÃO JUNIOR, A.A.; IGLESIAS, A.C.G.; MORANDI, M.V.; CHIARELLO, P.G. Effect of different dietary levels of vitamin $\mathrm{E}$ on lipid peroxidation in rat. Arch. LatinoAm. Nutr., Caracas, v.47, n.1, p.34-37, 1997.

VELIOGLU, Y.S.; MAZZA, G.; GAO, L.; OOMAH, B.D. Antioxidant activity and total phenolics in selected fruits, vegetables and grain products. J. Agric. Food Chem., Washington, v.46, p.4113-4117, 1998.

VISON, J.A.; HAO, Y.; SU, X.; ZUBIK, L. Phenol antioxidant quantity and quality in foods: vegetables. $J$. Agric. Food Chem., Washington, v.46, p.3630-3634, 1998.

WANG H.; CAO, G.; PRIOR, R.L. Total antioxidant capacity of fruits. J. Agric. Food Chem., Washington, v.44, n.3, p.701-705, 1996. 
WETTASINGHE, M.; SHAHIDI, F. Evening primrose meal: a source of natural antioxidants and scavenger of hydrogen peroxide and oxygen-derived free radicals. $J$. Agric. Food Chem., Washington, v.47, p.1801-1812, 1999.
WU, X.; BEECHER, G.R.; HOLDEN, J.M.; HAYTOWTTZ, D.B.; GEBHARDT, S.E.; PRIOR, R.L. Lipophilic and hydrophilic antioxidant capacities of common foods in the United States. J. Agric. Food Chem., Washington, v.52, n.12, p.4026-4037, 2004.

Recebido para publicação em 27 de abril de 2007 Aceito para publicação em 17 de janeiro de 2008 